\title{
Discussion of the Enhancing of Social Practice and Engineering Leadership: A case of the Activities of the "National Highway Traffic Safety Science and Technology Action Plan"*
}

\author{
Chuan Chen, Shanshan Sun \\ School of Transportation Engineering, Tongji University Room 333, Jiaoyun Building, No.4800, Caoan Road, Shanghai, China \\ chenchuan_tj@126.com, lavender_sss@163.com
}

\begin{abstract}
Social practice is an important way for engineering students to improve their engineering leadership. This article takes engineering students' participation in the "National Highway Traffic Safety Science and Technology Action Plan" as an example, focusing on its features and needs, to explore specific paths for social practice in related professional fields and enhance the engineering leadership of engineering students. Other Chinese universities in "Excellent Engineers Training Plan" can use results of this article for reference.

Index Terms - Engineering Leadership, A Plan for Educating and Training Outstanding Engineers, National Highway Traffic Safety Science and Technology Action Plan
\end{abstract}

\section{Introduction}

The rapid development of science and technology in the 21 st makes new requirements on the qualities and abilities of engineering students. To this end, USA firstly proposed the educational concept of enhancing the project leadership of engineering students. In 2004, National Academy of Engineering (NAE) and National Science Foundation (NSF) together published the report of "The Engineers of 2020: Visions of Engineering in the New Century". This report concluded that with the continuously improving of interdependence among technical, economic and social basis, the opportunities of the engineers to play their leadership role would increase greatly. The leadership of engineers will not only contribute to development and application of new technologies to solve future problems, but also have an important impact on the formulation of public polities and the management of government and industry. ${ }^{[1]}$

In recent years, more and more universities in USA take developing engineering leadership and training future engineering leaders as the purpose of undergraduate engineering education. For example, Massachusetts Institute of Technology (MIT) launched many engineering leadership training projects, committing to enable students to play to their capacity adequately and help them to achieve their personal goals and become excellent engineers. MIT enhance students' engineering leadership through two key factors: create situational circumstances for practice and guide others' activity. ${ }^{[2]}$ Recently, China has also gradually emphasized on leadership training of engineering students. In 2010, “A Plan for Educating and Training Outstanding Engineers", initiated by the Ministry of Education, is committed to train all types of high quality engineers who have strong innovation ability and can adapt themselves to needs of economic and social development. This plan can also lay a solid advantage in human resources for building an innovative country to achieve industrialization and modernization. Tongji University as the first member of "A Plan for Educating and Training Outstanding Engineers" has fully carried out the plan. This article discuss the problem of enhancing the students' engineering leadership in the practice through the example that students in School of Transportation Engineering of Tongji University who participated in the activities of the "National Highway Traffic Safety Science and Technology Action Plan".

\section{Participation in the Project Survey Practice Activities - Find Problems and Research Needs}

In February 2008, an important transportation research and social practice project, National Highway Traffic Safety Science and Technology Action Plan (NHTSSTAP), is established by the National Ministry of Science and Technology, the National Ministry of Public Security and the National Ministry of Communications. This plan aims at building a safe and harmonious road traffic environment, giving full play to the important supporting role of technological innovation on traffic safety and setting up a system which lines with national road traffic safety technologies, standards, measures and capacity for sustainable development. The specific objectives are to improve ability to response natural disasters and emergencies and achieve the goals like decreasing road traffic deaths year by year, reduction of serious traffic road accidents, million vehicles mortality rate closes to the level of moderately developed countries and so on. ${ }^{[3]}$

Teachers and students in the School of Engineering Transportation of Tongji University participated in the third subproject "Traffic Safety Science Demonstration Program of Activities for different groups of people", belonging to the

\footnotetext{
* This work is partially supported by National Key Technology R\&D Program, China
} 
fifth project "technology and demonstration for improving whole citizen's traffic safety behavior" in NHTSSTAP.

In nearly 10 cities of different types in Shandong, Zhejiang and Guangdong Province, graduates participated in investigation of publicity and education of traffic safety. In the process of investigations, they had a broad and in-depth communications with traffic police and primary and secondary school teachers. These practices firstly enhanced the understanding of the social status quo of traffic safety education, secondly improved the ability to collect data and analyze problems and thirdly summarized out our main problems in terms of traffic safety education. Its main problems are imperfect traffic safety education system, nonsystematic traffic safety education materials and teaching products, less population covered by traffic safety education, lacking social support to traffic safety educators and traffic police, etc. To solve these problems, the graduates have given relevant advice and suggestions.

Searching problems and solviing them are the basic abilities for an excellent engineer, and to guide students to observe, discover and analyze problems in research activities is the basis to solve the problems, which will stirring up and guide students' positive attitude in active learning.

\section{Participation in the Traffic Safety Teaching Products Design Competition - Stimulate Innovation Capacity}

At present, the research found that, compared with other countries, China is lack of teaching products designed for traffic safety education. Other countries have developed various forms of teaching products for different groups of people, such as traffic safety toys for children, traffic safety software for teenagers, products which are conducive to the traffic safety designed for the aged and so on. In order to develop traffic safety teaching products which are suitable for different types of people in China, the School of Transportation Engineering in Tongji University organized the Traffic Safety Teaching Products Design Competition. It gave full play of students' imagination and enhanced the innovative capability of the engineering students. Many students majoring transportation and others participated in this competition. Because most of them formed a team freely, students could practice their teamwork skills. In the process of the competition, students used their professional knowledge and imaginations, combined with their own life experiences and feelings, and then designed a variety of traffic safety teaching products. These products contain edutainment for children, cartoons for public information broadcast and reflective wristbands and reflective shopping bags for the aged, etc. The Magic cube with traffic sign and Traffic safety education chess won first prize in the traffic safety teaching products design competition, which is popular in primary and secondary school students in R \& D trial. These teaching products also became the most popular ones in the whole National Traffic Safety Education and demonstration activities. (Figure 1,2)
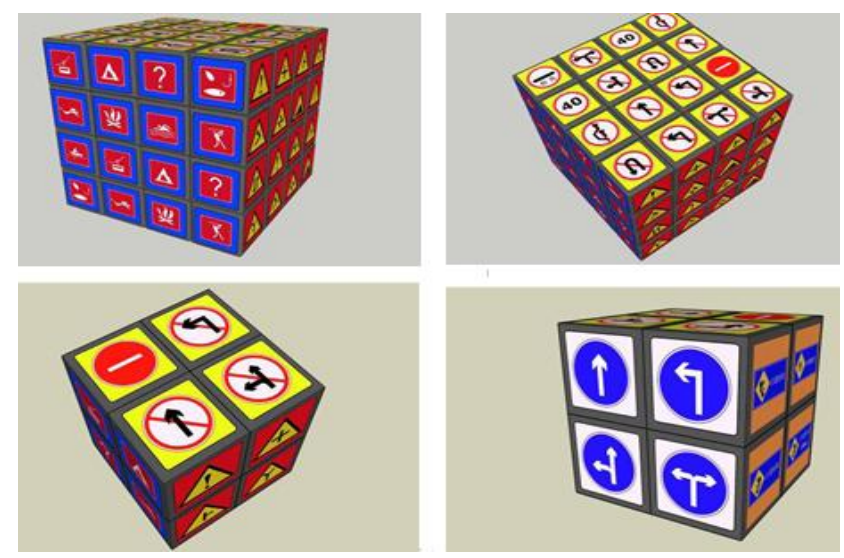

Fig. 1 Magic cube with traffic signs
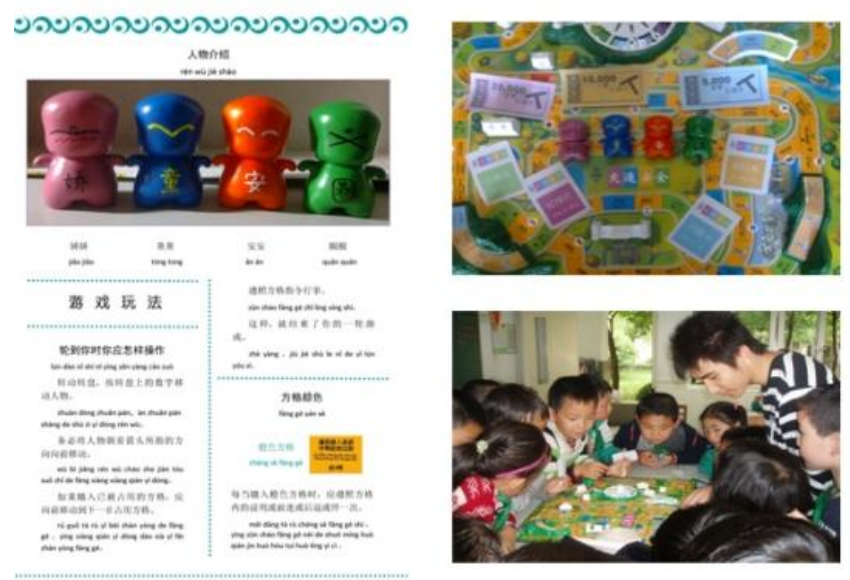

Fig. 2 Traffic safety education chess

Engineering students' innovation ability needs to be inspired and advocated continuously in educational practices, and it also needs to create conditions, scenarios and opportunities to train the students. Then they can gain knowledge in the activities, grow up in the difficulties, enjoy the happy of innovation activities in the achievement, stimulate the continued ability to innovate in the application and practice and generate intrinsic motivation of participating in innovation activities actively. Practices have proved that students who participated in the traffic safety teaching products design competition are very happy to improve their designs continuously in the traffic safety education practice and intend to continue developing related series of products.

\section{Participation in the Traffic Safety Education Research of Different Groups of People - Improve the Research Capability}

Trough survey, the students also found that traffic safety education in China is too broad and too theoretical to be accepted. It not only lacks systematic education for specific traffic behavior characteristics of different groups, but also lacks teaching plans with vivid expression of these elements. The traffic police at the frontline require traffic safety education content and lesson plans of different groups very 
much. Tongji University organized the graduates in School of Transportation Engineering to carry out research on the traffic safety behavior and problems of different groups. On the basis of investigation and study, from the advanced experience and means of education of developed countries, they compiled the "Traffic safety education content manual" for 10 groups of children, pupils, middle school students, elderly people, countryman, professional drivers, migrant works, motor cyclists and civil servants. They also compiled "Traffic Safety Education Training Manual" for the majority of traffic safety educators. These manuals are the first specialized series of traffic safety educational content and training materials, and now these materials could be gained by public through the National traffic safety public education website.

The research capability of engineering students can be improved by many methods, and observing, collecting realistic data, finding out the problems, then targeted researching in the social practices is an important ones. The graduates of Tongji Universities participated in the traffic safety education research for different groups and have finished the research process of theoretical analysis from theory to practice and then re-used in practical applications. Also, they used some of the results to write research papers published in professional journals. For instance, "Traffic Behavior Observation and Characteristic Analysis for Shanghai Primary School Students" has been published on the "China Safety Science Journal". This paper, by observing the traffic behaviors of primary school students, analyzed their insecurity factors and the problems which should be paid attention. The results of this study directed the design of the "Traffic Safety Education Training Manual for Primary School Students". In short, the capability of analysis and research is one of the most basic ability in qualities of engineering leadership. The students' participating in the traffic safety education practices and studying deeply for the needs of the community not only could improve their research capacity, but also strengthen the awareness of apply research results to serve the community.

\section{Participation in the Activity Designs and Exemplary Implementations of Traffic Safety Education - Enhance the Engineering Leadership}

The engineering leadership is a comprehensive capacity of a variety of elements, which mainly include visioning (reflects the value), analyzing (reflects the level of expertise and consolidated basis), Inventing (reflects the integration of social and technical elements) and relating (reflects the abilities of resources integration, communication and influence). Among them, inventing and relating are less involved in the university theory courses but more suitable in the social practice "learning by doing". The activities of "National Highway Traffic Safety Science and Technology Action Plan" provided a good opportunity to "learning by doing" for the students in Tongji University.

The research topic of "Technology and Demonstration of Universal Enhancing of Traffic Safety Behavior" asks for the applying of research achievements on traffic safety education practice, rather than "on papers". And it also requests new content designed to meet the traffic safety educational needs for different groups new forms of activity that the learned are willing to participate and new forms of activity that are easy to put into effect. Under the guidance of their teachers, graduates of Tongji University collected and analyzed national and international contents and forms characteristics of the traffic safety education activities widely, which strengthened the learning of psychology, education, management, communication and advertising. Also, they applied their own designs of teaching materials of traffic safety education for different groups of people and through using basic theory of multi-disciplinary synthetically and support from modern multimedia educational tools, and the same time they designed a traffic safety education program of activities by using the way of modular combination and processing operation for 10 groups of children, pupils, middle school students, elderly people, countryman, professional drivers, migrant works, motor cyclists and civil servants. Next, they put their program of activities of traffic safety education into practice and sought recommendation of organizers and participants in the demonstration cities. For example, in Binzhou, Shandong Province, a truck driver said, "The way of playing videos is good, but the time is too long". Also in Linyi, Shandong Province, an elderly man said, "I love the way of finding mistakes in the picture, but some pictures are not clear". Considering advices of different groups of participants and organizers, the students repeatedly revised and improved their activity design and ultimately formed the set of the program of activities and training programs of activity implementation process. In the end, the students won a great praise of the majority of traffic safety education organizers and executors. Figure 3 shows traffic safety education program of activities and implementation designed by the graduates of Tongji University.

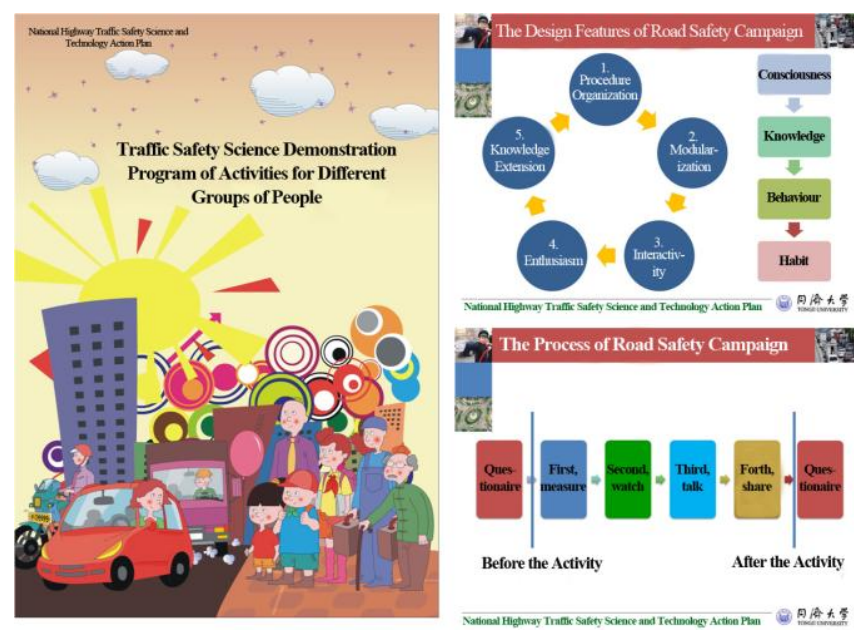

Fig. 3 Traffic safety education program of activities and implementation designed by the graduates of Tongji University

The process of organizing, contacting and implementing the traffic safety education activities is a procedure of making 
the ideas into realities. In this process, students' abilities of comprehensive coordination have been trained. The process of implementing activities requires students to take full account of the variety of factors and communicate, contact, explain and persuade with different kinds of people. For implement environment of different regions, the students also need to consider all details in advance, from the design of the promotional language to the preparation of wiring plug, from the debugging of electronic equipment to the design of the guiding flag, etc. A traffic safety education activity only needs one host, but needs 5-6 students to assist. "Even considering as thoughtful as we can, we always have flaws in every exemplary demonstration", the students said. They summarized without delay, and then improved the way of communication and process of implementation constantly. For example, the questionnaire survey before and after the activities changed into be filled in by the investigators from by themselves, and in order to help the traffic police the implementation of activities on the operation of the electronic teaching product equipment, the students made the process of equipment operation into videos, so the traffic police can just play the videos in the activities. In 2011, by participating Traffic Safety Education Activities in nearly ten cities of Shandong, Zhejiang and Guangdong Province, the students exercised their communication skills and strengthened their capabilities of host and speech. The students also made their experience of the organization and implementation of these activities into implementing process instruction manual and it provides a good reference for the perpetrators of large-scale promotion of the future activities. A traffic police of Shandong Province said that this manual facilitated the organization of activities and the activity effects are easier to analyze and summarize. The students said, "By participating the traffic safety science education demonstration and activities, we harvested not only just happiness to see our research results put into practice, but, more importantly, we improved our capacity of communication, leadership and implementation in this active practice.

\section{Conclusion}

Compared with other developed countries like USA, Germany and Japan, China has been gradually entering the automotive era in recent years. In China, the improving of universal awareness and behavior of traffic safety will be a systematic and continuing education process. "National Highway Traffic Safety Science and Technology Action Plan" is an educational, research and practical activity which will be continuously and deeply promoted. In the process of participating this social practice, the students of School of Transportation Engineering in Tongji University have used and expanded their professional knowledge, improved the capability of research and innovation, strengthened the awareness of serving the society and exercised and enhanced their engineering leadership. Also in the progress of training excellent Chinese engineers, the society, universities and teachers should encourage and support the majority of engineering students to enhance their engineering leadership. That is because practical experience is the most direct and fundamental experience and it's also the field experience that an excellent engineer must accumulate in the process of growing.

\section{References}

[1] National Academy of Engineering. The Engineer of 2020: Visions of Engineering in the New National Academy of Engineering. The Engineer of 2020: Visions of Engineering in the New Century. Washington D.C. The National Academies Press, 2004, pp. 201.

[2] Jun Cui, Xia Wang, Luwen Gu. The Concept and Practice of Engineering Leadership Education in the United States. Higher Education Development and Evaluation, vol. 9, pp.77-84, 2010

[3] Jianke Jiang. Improve Ability to Response Natural Disasters and Emergencies, National Highway Traffic Safety Science and Technology Action Plan Starts. People's Daily, 2008(2/23, pp. 2)

[4] Yichun Wang, Chuan Chen. Analysis and Suggestion on the Propaganda and Education of Traffic Safety. Road Traffic and Safety, vol. 8, pp. 1216,2009

[5] Xuesong Wang, Li Wang, Renxin Lin, Dongyuan Yang. Traffic Behavior Observation and Characteristic Analysis for Shanghai Primary School Students. China Safety Science Journal, vol. 12, pp.122-129, 2010

[6] Weiwei Ye, Min Ye. On Key Elements of the Engineer Leadership. high engineering education, vol. 5, pp. 91-95, 2011 